\title{
BUILDING SOCIAL CAPITAL THROUGH HOME-SCHOOL COOPERATION
}

\author{
Karin Lukk and Marika Veisson \\ Tallinn University, Estonia
}

\begin{abstract}
The background to the study examines parental involvement in education as a form of social capital and focuses on how involvement may be developed through three dimensions of social capital: bonding, bridging, and linking. Both groups (students and parents) were surveyed using questionnaires. The data of two different studies have been used: a cross-sectional study carried out in sixty-five schools in Estonia and a study of a comprehensive school to introduce practical implementations of the findings. The results of the studies indicate a high degree of readiness for cooperation from both sidesparents and the school, even though their understanding of responsibilities slightly differ. Parents and teachers should have mutual power and influence regarding the child's education, although schools have to take the prime responsibility in organizing the cooperation process.
\end{abstract}

Key words: parental involvement; social capital; home-school cooperation; family relationships; school climate.

Current discourse in education acknowledges the partnership between parents and school. The increased interest in the relationship between home and school is one of the most positive educational developments of the past decade. Today, at all levels of education, there is overwhelming agreement that parents have a valuable role to play in the education of their children. Parental involvement is promoted at government level (Nassar \& Rebane, 2002) and the prevalent culture of rights encourages parents to exercise their rights in the field of education.

The term 'involvement' is often used in this context synonymously with the words 'partnership', 'participation', 'collaboration' or 'cooperation'. But there seems to be a consensus in all these explanations: home-school partnership or cooperation is a working relationship that is characterized by a shared sense of purpose, mutual respect, and the willingness to negotiate (Godber, 2002). The basis for a good relationship lies in communication and the gate-keepers of it are teachers. The teacher is an initiator, a coordinator, and an evaluator of the process. The majority of parents want their children to be successful at school but many parents do not know how to assist their children in ways that improve school performance (Hill \& Craft, 2003). Managing these tasks requires a new type of knowledge compared to the one that traditional teacher 
training programs provide. The changes in teacher training (especially since the middle of the nineties) have mostly been connected with the ideas of learning organization and child-centeredness; less attention has been paid to a systemic approach, team work/ cooperation and consulting skills - which are essential for building an effective homeschool collaboration system; therefore these changes should be included in both teachers initial as well as in-service training.

Emphasizing the importance of home-school collaboration creates a new concept of educational development - viewed together with the other three parties at school: administration, teachers, and students it forms a holistic approach which in turn is one of the prerequisites for implementing the idea of sustainable development. The holistic meaning of sustainable development embraces the integration of different aspects economic, environmental, social, and cultural, broadening it beyond the primary concern for the environment as it is generally understood (United..., 1996). The study of Raudsepp (2006) showed that the cultural and the social aspects of sustainable development have not been paid enough attention to in education, although education has a vital role in achieving objectives with respect to sustainable development in all parts of society as it supports forming people's values and behaviour (United..., 1996). Therefore the teachers could be seen as policy makers and teacher training faces another important task - to train teachers for working with different audiences in order to target as many sectors of society as possible. Public awareness and understanding of sustainable development is one of the highest priorities of United Nations (United..., 1996), therefore educating parents is definitely an inseparable part of educational process at school. Involving parents has a dual purpose: it helps to encourage a new consciousness and directs both parents' attitude, their values and behavioural changes towards establishing more sustainable lifestyles and, on the other hand, parents become educators themselves imparting the idea of sustainability to their children.

Parent involvement has been identified as a primary component of school climate, and is also linked with key educational and social-emotional outcomes for students and also their school performance. Much research has proven its positive impact on child's academic improvement (Cassel, 2003; Cordy \& Wilson, 2004; Eddy, 2004; Fantuzzo, 1999; Hill \& Craft, 2003; McNeal, 1999; Peraita \& Pastor, 2000; Shepard \& Carlson, 2003). But at the same time it is not simply parental involvement in children's education that matters for the improved academic achievement, rather it is the production of social capital through specific human interactions in the school. Social capital or social connectedness has been defined as the cultural resources and interpersonal bonds shared by community members (Jack \& Jordan, 1999). Parental involvement can be conceptualized as a form of social capital that provides individuals with access to resources that improve their academic achievement.

Like other forms of capital, social capital is a resource that students may draw upon when they need to enhance productivity. One of the primary functions of social capital is to enable a student to gain access to human, cultural, and other forms of capital, as well as to institutional resources and support (Coleman, 1988).

There has been much discussion of the concept of social capital since it was introduced by Coleman (1994) as an extension of prior research on financial and human capital. Whereas financial capital describes a family's wealth or income, and human capital is measured by parents' education (especially by mothers' education), Coleman defines social capital by referring to its function, viewing social capital as a resource 
that can be drawn from. Bourdieu (1986) defines social capital as a resource made up of social obligations (or connections), which is convertible, in certain conditions, into economic capital. Later the definition of social capital was refined (Perna \& Titus, 2005) to include the norms of reciprocity and trustworthiness that exist in the social networks of individuals.

Coleman (1994) and Bourdieu (1986) offer two somewhat different conceptualizations of social capital. Coleman's approach stresses the role of social capital in communicating the norms, trust, authority, and social controls that an individual must understand and adopt in order to succeed. Coleman's approach is most frequently used in educational research (Perna \& Titus, 2005) as it is wider (compared to Bourdieu's) and therefore useful for operationalisation in the frame of an empirical and quantitative study. Coleman identifies the ways in which parental involvement can build social capital, suggesting that social capital is derived from two types of relationships: the relationship between a student and his/her parents; and relationships between a student's parents and other adults, particularly adults who are connected to the school that the student attends (Coleman, 1988).

Bourdieu (1986) focuses on the ways in which some individuals are advantaged because of their membership in particular groups. According to him, the amount of social capital to which an individual may gain access through social networks and relationships depends on the size of the networks as well as on the amounts of economic, cultural, and social capital that individuals in the network possess. Bourdieu views social capital as a mechanism that the dominant class uses to maintain its dominant position (Lin, 2001). Bourdieu's use of the term is narrower than Coleman's, seeing the effect of social capital at an individual level only and therefore it cannot be viewed as the best approach to describe the home-school relationships supporting child's development.

Drawing on the work of Coleman and Bourdieu, Lin (2001) developed a theory of social capital that focuses on the mechanisms and processes through which an individual obtains the resources that are embedded in social networks. Lin suggests that, whereas closed networks, or strong ties, may effectively preserve resources, weak ties may enable an individual to access resources that are not available via strong ties. In other words, weak ties may serve as a "bridge" to networks that possess information and resources different from those that are provided by strong ties or by an individual's family and close friends (Lin, 2001). Lin assumes that, although individuals generally establish relationships with individuals who have similar perspectives and socioeconomic backgrounds, some individuals seek relationships with individuals who are of a somewhat "better" social status in order to gain additional resources (Perna \& Titus, 2005).

Most scholars argue that social capital is not a single entity that families either have or do not have (Woolcock, 2001). Rather, it is multidimensional, existing on at least three dimensions. The first dimension is bonding, which refers to homogeneous relationships within a close group - for example, within the family between parent, children, and kin (Woolcock, 2001). Bonding social capital provides a sense of belonging and is critical to the sense of well-being of the members of families and groups and fulfils immediate need for belonging, love, emotional support, and solidarity. Terrion (2006) in her study of the connections forged between members of a temporary group stated that a sense of belonging was central to the development of cohesiveness in the 
group and that it was created through the group members' communication with each other.

Bridging, the second dimension, refers to connections with diverse social groups: heterogeneous relationships with more distant friends, relations, and neighbours. Woolcock (2001) sees bridging as a horizontal metaphor, meaning that connections are made outside of the immediate network but with those who are similar in terms of demographic characteristics, including socioeconomic status, beliefs and values, life experience, and existing social capital.

Linking social capital, the third dimension, contributes a vertical dimension. It is the addition of linking social capital to bonding and bridging that is vital to the achievement of the positive outcomes associated with social capital (Terrion, 2006). Although bonding and bridging connect the parents of different groups with new contacts, linking social capital provides opportunities for families in the form of access to advice, resources, and information; it helps to develop linkages with individuals in positions of power.

Considering these three different approaches to social capital with regard to its three dimensions, some links could be drawn out - Coleman's approach seems to deal more with bonding dimension as it is based on strong ties, close relationships while Lin assumes both kind of ties, strong and weak, to have their certain roles in building of social capital, which in turn describes the main content of bridging dimension. Bourdieu's point of view, dealing with the questions of power and dominancy, is more focused on vertical relationships and therefore discusses the problems of the third dimension linking.

\section{The research questions and methods}

The current article provides a survey of two studies: one of them may be seen as a scientific foundation and the other as its practical expansion at a grass-root level. The first one was a cross-sectional study carried out in Estonia in 2004 by university scholars. The results of the research were introduced at different conferences (Lukk, 2005a) and they encouraged some of the headmasters/head teachers to start the reorganization process at their schools. The results presented in the article are based on the data of the study, which was carried out in one of the biggest public comprehensive schools in Estonia in 2005.

The focus of the university study included school factors that presumably had a connection with either students' truancy or their low academic achievement. The underlying question of the study was how and to what extent could school support students' coping and prevent their dropping out and other unacceptable behavioural outcomes. The study embraced many aspects of the school climate and the learning environment, investigating the opinions of school leaders: headmasters and head teachers, teachers, students, and also parents. The data were gathered using self-report questionnaires. The questionnaires to all examined parties (school administration, teachers, students, and parents) consisted of the same content blocks about the questions studied. The blocks embraced a wide range of different aspects connected to the school climate and the learning environment.

The sample was composed of 65 schools in Estonia (10\% of all schools). The number of participants included 120 representatives of school administrations, 624 
teachers, 3838 students from 7th, 9th, and 11-12th grades, and 2048 parents. The respondent schools formed an adequate representation of schools both geographically, according to the language of conduct (Estonian or Russian $(27 \%)$ ), and concerning the results of state exams during the last three years (the best and the weakest results in their area - county or city). Full anonymity was guaranteed for all participants (both individuals and schools in general).

The aim of the comprehensive school's study focused on home-school cooperation and the main question was what should the school do to achieve a better cooperation with parents in order to support children's coping at school. The method of the research was a questionnaire to parents and it embraced different aspects: the main learning orientations of the school; student's daily routine at school; student-teacher relationships; communication between home and school; different forms of home-school cooperation; extra-curricular activities. The sample consisted of 504 parents ( $86 \%$ women and $14 \%$ men).

The analysis was based on quantitative research methods ( $\mathrm{f}$ - and $\mathrm{t}$-tests were used to compare means and dispersion; regression analysis for a connection model; factor and cluster analyses for grouping).

The results of both studies have been discussed in the framework of social capital, through its three dimensions (Woolcock, 2001).

\section{The first dimension: Bonding}

Bonding describes the relationships within a family. According to Coleman's (1988) perspective on social capital, parents play a primary role in promoting the attainment of their children. Close relationships within family are based on caring, effective communication, shared goals, values, and expectations.

Comparing the opinions of parents and children about caring in the family shows a statistically significant difference $(\mathrm{p}=0.000)$ (Figure 1$)$. Children tend to assess the level of caring lower than parents do. More than $20 \%$ of children stated that they do not/rather not agree that the members of their family care about each other.

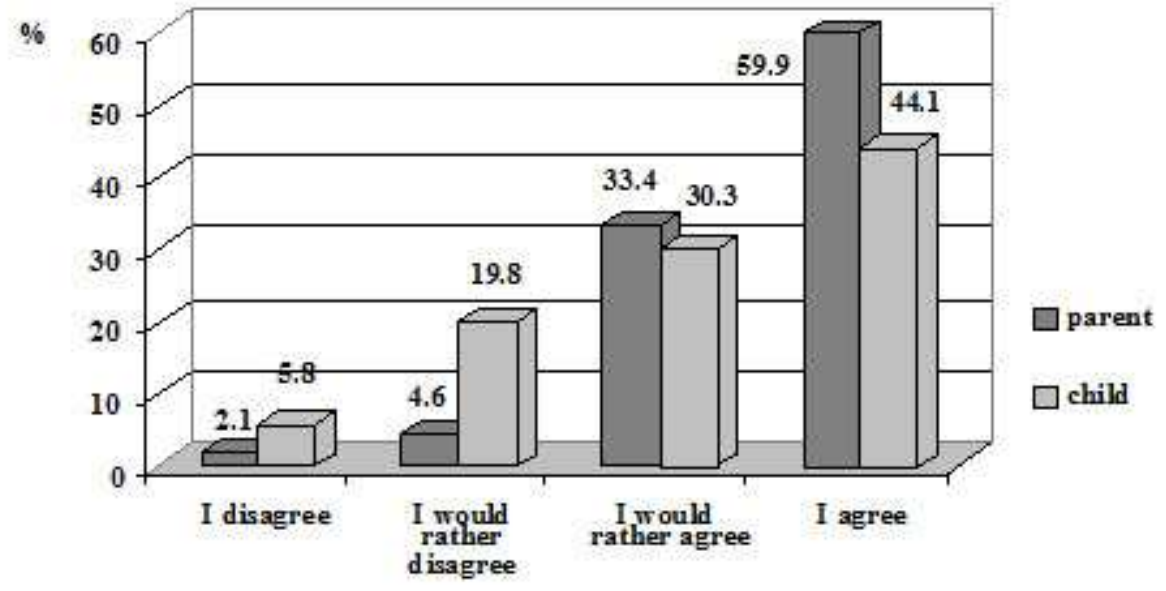

Figure 1. The family members care about each other 
One of the reasons may be that the relationships between siblings are often problematic especially at adolescent age. However, it is a quite serious fact if only less than half of the students can express their complete agreement with the statement.

$9.5 \%$ of the children said that they had experienced violence at home lately and only $5.1 \%$ of parents stated that about their child (the significance of the difference was $\mathrm{p}=0.008)$.

One of the questions studied the different aspects of child's life that parents are concerned about. The results revealed that $18.6 \%$ of parents worry about the relationships in their family. Parents from Russian schools and from schools in the capital city showed much higher percentages (36\% and $23.5 \%$ accordingly) comparing to parents from rural or country regions $(13 \%)$, which may be due to the more stressful lifestyle. People living in the capital city have to manage in a much busier environment and face more challenges in their daily life. Russian parents tend to feel quite uncertain in our contemporary society (Lukk et al., 2006) about their future and about their children's coping in their future lives. Having that uncertainty in their minds as an underlying factor of distress may also cause tensions in their family life.

Communication plays a pivotal role in the production of social capital (Terrion, 2006). The analysis of the difference between parents' and children's opinions about the school revealed a statistically significant $(\mathrm{p}<0.01)$ difference in their views on some characteristics (Figure 2). The most remarkable differences were about the clear aims of the school and whether new teaching methods and techniques are used in teaching process or not.

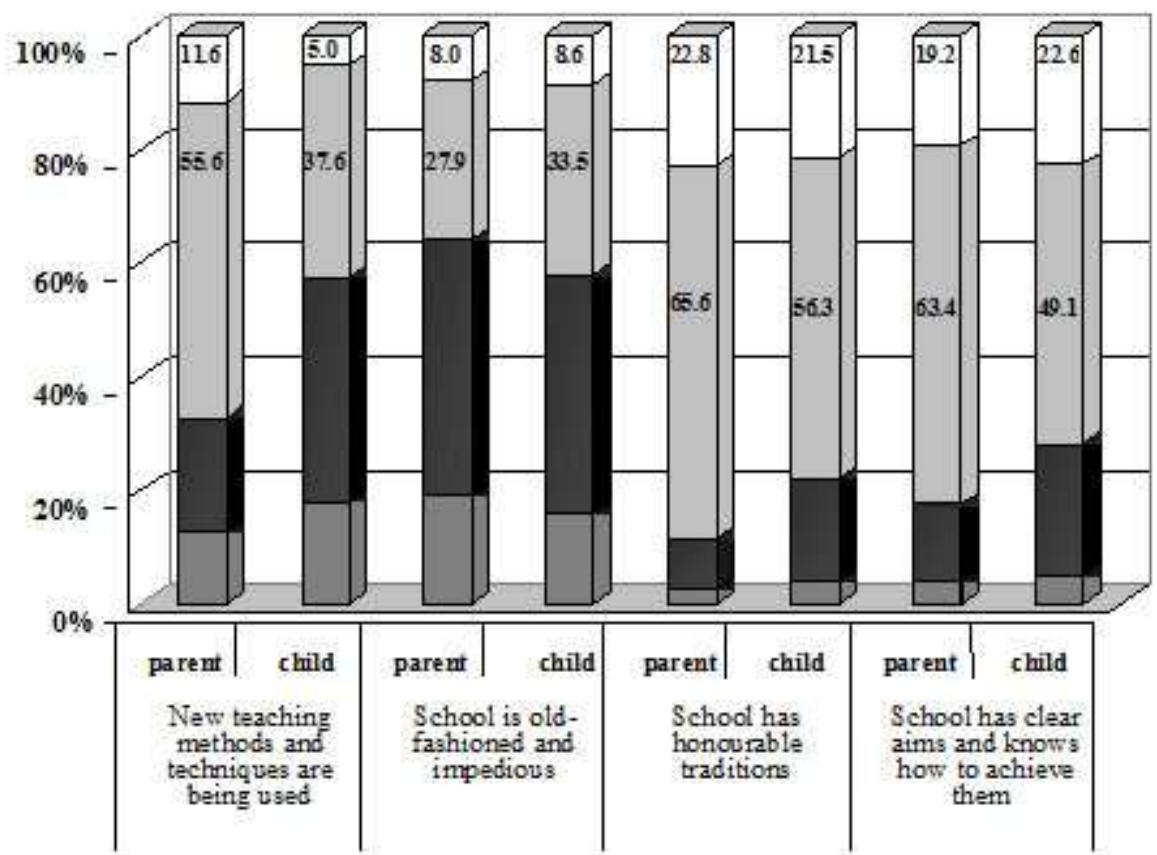

I comp letely disagree

- I disagree

$\square \mathrm{I}$ agree

I absolutely agree

Figure 2. Parents' and children's opinion about the school 
Most of the parents $(82.6 \%)$ support the statement that the school, their child attends, has clear aims and knows how to achieve them. But at the same time only $71.7 \%$ of children seem to know that - which shows an information gap on that point. The same trend appears in the question about the new teaching methods and techniques as well (67.2\% of parents and $42.6 \%$ of children).

Ranking the sequence of the topics, that families discuss, showed that in most cases parents and children talk about school, which may seem as a very positive fact. But at a closer look it turns out that the main subject of these discussions is grades, not deep conversations about learning in general, about the things children study at school, or about how they have developed. In the context of social capital this means that a lot of resources have been left unused. Talking about grades does not deliver the message about the importance of education; it does not show the right way to choose as it does not lead the child to self-assessment; it does not help him or her to learn to set goals, to work out the plan, to carry it out, and to draw conclusions - it does not help a child to learn the process of learning.

\section{The second dimension: Bridging}

A primary function of social capital is to enable a student to gain access to human, cultural, and other forms of capital, as well as to institutional resources and support (Perna \& Titus, 2005). Although the family has an important role as a resource of social capital, it cannot be viewed as the only one. According to Bronfenbrenner's (2000) theory, the network, a child is connected to, is much wider and therefore while talking about bridging we move to the next sphere - school. School is an institution where children spend quite a large amount of their time. Coleman (1994) stresses the relationship between a student and his/her parents, but also the relationships between a student's parents and other adults, particularly adults who are connected to the school that the student attends: teachers and other parents. One may argue that the ties are much weaker in school community than they are in family and therefore they are not of such a great importance. But the weak ties may serve as a "bridge" to networks that possess information and resources that are different from those that are provided by strong ties or by an individual's family and close friends (Terrion, 2006). Therefore the role of teachers as network coordinators cannot be underestimated.

Social capital is built on a foundation of trust (Jack \& Jordan, 1999). Studying how much parents trust the school their child attends showed that most parents $(79.5 \%)$ trust their child's school and the teachers - the average index of trust was 4.35 (on a scale of 1-6). Regression analyses also revealed that parents' general opinion of the school is mostly predicted by trust; the second and the third variables were parents' opinion of home-school relationships and child's willingness to go to school - which is one of the factors that determines joy of school.

Parents' opinions about teachers were grouped by cluster analysis and four different clusters were formed:

1) Student-oriented caring teachers: teachers who are interested in child's development, they monitor systematically student improvement; they think that assessing or grading is a tool to support child's learning process and the most important is a positive learning environment at the lesson. 
2) Positively strict teachers: teachers who maintain good discipline by being objective and reasonably demanding; student opinion is important for them; they think that grades are objective descriptors of child's development.

3) Subject-oriented teachers: teachers who have extensive knowledge in their subject and the most important for them is to prepare their students for their level tests and exams.

4) Strict competitors: teachers who consider punishment as the main factor influencing child's academic attainment; the base for development lies in competition; it is very hard for them to accept students who are too different from a "normal average".

These groups show clearly that there has been a shift towards child-centeredness in our schools, although a lot of work is still to be done to change the way of thinking of all teachers. The most important in that process is to have the general climate of school focused on child-centeredness and that would influence even the teachers who are still holding onto old-fashioned ways to try to keep up with the inevitable changes.

The forms of home-school cooperation vary greatly from school to school. The two main forms are parents' meetings and parent-teacher discussions (Lukk, 2005b). The study showed that parents expect some changes in that field - they would like their child to attend the meetings or parent-teacher discussions as well; they would like to visit the classes; to have some kind of a parent organization.

The study of the comprehensive school revealed quite similar results - parents asked for more openness and child's presence while his or her development is being discussed. The evidence showed that parents cared deeply about their children's school progress and they wanted to know more about children's learning, but they did not want to share the teaching responsibilities with teachers. Parents clearly suggested that they needed more guidance and explanation. They wanted to learn more about what the schools' aims were and how children learn.

Parents expected schools to cover the basic aspects for parental involvement, such as simple and understandable communication about children's progress and problems, while their obligations should include encouraging their children to get the most out of school experiences. The parents' responses suggest that they believe schools and parents have different tasks and roles. However, parents suggested that having different tasks should not prevent them from complementing each other. Exchange of information is welcome and needed, but $30 \%$ said the schools' obligations should include "providing high quality education" and "taking the responsibility to guide them through educational activities".

The parents of that particular school also suggested having some kind of a parent organization. After preparing for about half a year, a new system was implemented in the school - the parents of one age-group children (i.e. the parents of 7-th-grade students) formed a so called "education club" where different topics about child development and educational problems are discussed. The club meetings take place once a month and are extremely popular among the parents of teenagers.

The analysis revealed that parents' opinions were generally very consistent with what they needed and wanted from the school in terms of both effective parental involvement and effective education for their children. But at the same time the respondents were often troubled and confused, and their responses were sometimes even contradictory. Parents clearly lacked sufficient knowledge about the schools and their financial 
constraints. However, according to parents, clear communication is a crucial point for parental involvement and this may provide a significant means by which parents and schools may start to develop effective relationships in the future.

\section{The third dimension: Linking}

Social capital focuses on social networks and the ways in which social networks and connections are sustained (Perna \& Titus, 2005), it is acquired through individual's relationships with other individuals, particularly through membership in social networks and other social structures. Linking social capital embraces individual's relationships with social structures on a vertical line, which in schools mean the parental involvement in different events, meetings, schooling organized by schools and parent organizations.

The underlying prerequisite of the effective functioning of that vertical line is the characteristics of the school: specifically, the extent to which the school encourages parental involvement, the volume of resources that may be accessed via social networks at the school, the homogeneity of the social networks at the school, and the school climate in general (Perna \& Titus, 2005).

In the current study parents assessed schools by different variables, which were analyzed by factor analysis. Three factors were extracted:

1. Respectable/Honourable schools (descriptive power $34 \%$ ): schools with a strongly inclusive and democratic leadership style; the school has well-established aims, strong traditions, and a good reputation; at the same time they are opened to new ideas.

2. Progressive schools (descriptive power 24\%): open-minded and forward-looking, these are the schools that keep up with the demands of the modern society; the leadership style is clear and objective - involving all interest groups.

3. Impeding schools (descriptive power 13\%): schools that still hold onto oldfashioned ways and habits; implementing new ideas or views is an extremely slow process; students are regarded and treated according to their socio-economic status.

The results reveal that most of the schools have recognized the necessity for change, try to be opened and to involve different interest groups in school development. But all changes take some time until they function without serious problems. So there are still some reasons that hinder effective home-school cooperation. Researches have shown (Lukk et al., 2006) that parents who have been ready to cooperate have lost their willingness because of the negative experience with school. The number of parents who either cannot find time or are not interested is quite large, but it still cannot be an excuse for no home-school cooperation at all. Knowing these facts it is now school's both administration and teachers - obligation to become an active party of the process organizing the work in a way that would motivate parents to participate.

The research carried out in the comprehensive school helped school administration to implement some very important changes. Studying the aspects of a "vertical line" and including parents in the process of drawing up the developmental plan for the school, it turned out that parents were very concerned about primary school children's afternoon time. Their suggestion was to find the way to look after children until their parents come home from work - which means until about 5 o'clock. This idea led the 
school to introducing an absolutely new system - The Afternoon School. Primary school children (grades 1-4) can spend their time under supervision in different activity centers reading center, drawing center, film center, and playing center. The new system has been launched by parents and it has had a great impact on the reputation of the school.

Once parents and teachers realize their capabilities and roles, they can work together effectively in helping their children learn. A shift is needed from the paradigm of parents and teachers working separately to parents and teachers working together for the benefit of the child. The relationship between parents and teachers should be one in which both have mutual power and influence regarding the child's education. The existing cultural discontinuity can be addressed by the teacher shifting from - "telling to showing" parents what to do - by explicitly teaching parents to assume new roles (Musti-Rao \& Cartledge, 2004).

\section{Conclusion}

With the growing diversity in schools, the role of teachers, especially in urban schools, has changed dramatically, becoming decidedly more challenging. Teachers are under constant pressure from the school district to achieve established standards of excellence, making it essential to work collaboratively with parents toward a common goal of children's success in school. Instead of considering parents as a threat or nuisance, teachers have the opportunity to elicit help from parents. Just as more information about the schools allows parents to assist their children better, the more information teachers have about the children's home environment, the better equipped they will be to accommodate the needs of the parents and the children.

Parental involvement is only a factor of the more complex phenomena - social capital. Social capital is a term that has different explanations and exists on at least three dimensions: bonding, bridging, and linking. Different aspects of home-school cooperation in the framework of these three dimensions have been discussed in the article:

- the relationships within family as the indicators of bonding. The most important results were that more attention should be paid on caring between family members and parents should talk to the children about the importance of school and education instead of concentrating only on grades;

- parent-teacher communication and parents' opinion about teachers as aspects of bridging. Parents trust school and teachers but they expect them to be more open; varying the forms of home-school cooperation would provide more opportunities for parents to find the most suitable way of communication for them. A shift is needed from the paradigm of parents and teachers working separately to parents and teachers working together for the benefit of the child. Communication is the heart of the whole exchange process. Help and involvement may occur only when communication is recognized as the generator of fruitful relationships;

- school-related questions as part of the linking dimension. The results reveal that schools have recognized the necessity for change; they try to be open and involve different interest groups in school development. A very important aspect of parental involvement is an exchange of expertise and abilities. Schools provide parents with ideas on how to help their children with adequate attitude and interest, and they invite parents to become involved with curriculum matters such as planning, classroom activities, and children's assessment. 
The focus of efforts for both parents and teachers needs to be the educational success of the child. The relationship between parents and teachers should be one in which both have mutual power and influence regarding the child's education. It is essential that schools and particularly teachers recognize parents as assets. Only then we can speak about building social capital that enables parents to better support their children.

\section{References:}

Bourdieu, P. (1986) The forms of capital, in Richardson, J.G. (ed.) Handbook of Theory and Research for the Sociology of Education. New York: Greenwood Press.

Bronfenbrenner, U. (2000) Ecological systems theory. Encyclopedia of Psychology, vol. 3, 129-133. US: American Psychological Association.

Cassel, R.N. (2003) A high school drop-out prevention program for the at-risk sophomore students. Education, 123(4), 649-659.

Coleman, J.S. (1988) Social capital in the creation of human capital. American Journal of Sociology, 94, 95-120.

Coleman, J.S. (1994) Foundations of Social Theory. Cambridge: The Belknap Press.

Cordy, S. \& Wilson, J.D. (2004) Parents as first teacher. Education, 125(1). Retrieved October 29, 2005 from Academic Search Premier database.

Eddy, R.M. (2004) Effects of school size on student achievement. UMI Dissertation Order Number AAI3103774.

Fantuzzo, J. (1999) Introduction to the special issue: Beginning school ready to learn: Parental involvement and effective educational programs. School Psychology Review, 28(3).

Godber, Y.E. (2002) School climate: Understanding parent perspectives to strengthen family-school relationships. Dissertation Abstracts International Section A: Humanities and Social Sciences, 63 (6-A). US: Minnesota.

Hill, N.E. \& Craft, S.A. (2003) Parent school involvement and school performance: Mediated pathways among socioeconomically comparable African American and Euro-American families. Journal of Educational Psychology, 95(1), 74-83.

Jack, G. \& Jordan, B. (1999) Social capital and child welfare. Children \& Society, 13, $242-256$.

Lin, N. (2001) Social Capital: A Theory of Social Structure and Action. New York: Cambridge University Press.

Lukk, K. (2005a) Kooli ja kodu koostöö õpilaste toimetuleku toetajana [Home and school cooperation as a supporter of child's coping], in Kraav, I., Kala, U. \& Pedastsaar, T. (eds.) Haridus muutuste ja traditsioonide keerises [Education in the turbulence of changes and traditions]. Põltsamaa: OÜ Vali Press.

Lukk, K. (2005b) Parental involvement in the framework of holistic education. Journal of Teacher Education and Training, 5, 90-100.

Lukk, K., Veisson, M., Ruus, V.-R. \& Sarv, E.-S. (2006) Democratic approach to school development: Involving all interest groups. Journal of Teacher Education and Training, 6, 88-102.

McMillan, D.J. (2005) Close encounters: Issues in pre-school parental involvement in Northern Ireland. Child Care in Practice, 11(2), 119-134. 
McNeal, R.B. (1999) Parental involvement as social capital: Differential effectiveness on science achievement, truancy and dropping out. Social Forces, 78(1), 117-145.

Musti-Rao, S. \& Carledge, G. (2004) Making home an advantage in the prevention of reading failure: Strategies for collaborating with parents in urban schools. Preventing School Failure, 1045988X, 48(4).

Nassar, K. \& Rebane, E. (2002) Põhikoolist väljalangevus - kus oleme täna ja mis saab homme? Tallinn: Haridus- ja Teadusministeerium [Basic School Dropout - where are we today and what is waiting for us tomorrow? Tallinn: Department of Education and Science].

Peraita, C. \& Pastor, M. (2000) The primary school dropout in Spain: The influence of family background and labor market conditions. Education Economics, 8(2), 157169.

Perna, L.W. \& Titus, M.A. (2005) The relationship between parental involvement as social capital and college enrollment: An examination of racial/ethnic group differences. Journal of Higher Education, 76(5), 485-519.

Raudsepp, M. (2006) Sustainable development as an ambiguous regulative idea: A qualitative study in Estonia, in Pipere, A. (ed.) Education and Sustainable Development: First Steps Toward Changes, volume 1. Daugavpils: Saule, 31-42.

Shepard, J. \& Carlson, J.S. (2003) An empirical evaluation of school-based prevention programs that involve parents. Psychology in the School, 40(6), 641-656.

Terrion, J.L. (2006) Building social capital in vulnerable families: Success markers of a school-based intervention program. Youth \& Society, 38(2), 155-176.

United Nations Department of Economic and Social Affairs (1996) Commission on Sustainable Development: Promoting Education, Public Awareness and Training. Retrieved February 5, 2007 from http://www.un.org/esa/documents/ecosoc/cn17/ 1996/ecn171996-14.htm.

Woolcock, M. (2001) The place of social capital in understanding social and economic outcomes. Isuma, 2(1), 11-17. Retrieved November 5, 2006 from Academic Search Premier database.

* Data collection for the present study was funded by Estonian Education and Science Ministry: a state financed project "School as developmental environment and students coping” (reg. no. 0132495s03).

\section{Correspondence:}

Karin Lukk MA, Faculty of Educational Sciences, Tallinn University, Uus-Sadama 5, Tallinn 10120, Estonia. Email: karin.lukk@tlu.ee 